\title{
ALARGAMIENTO Y NÚMERO INALTERADO DE ENDOSOMAS TEMPRANOS EN LA ENFERMEDAD DE ALZHEIMER
}

\author{
ENLARGEMENT AND UNALTERED NUMBER OF THE EARLY \\ ENDOSOMES IN ALZHEIMER'S DISEASE
}

JOSÉ RAFAEL DÍAZ RUDAS

Universidad Norbert Wiener

\section{RESUMEN}

Los endosomas tempranos están alargados en las neuronas en la enfermedad de Alzheimer esporádica y en la trisomía 21. Esta alteración nunca ha sido cuantificada y los mecanismos de este alargamiento (fusión o dilatación de los endosomas normales) no han sido determinados.

Se estudiaron cerebros de cinco cadáveres humanos con registro de enfermedad de Alzheimer (grupo experimental) y cinco sin la enfermedad (grupo control). Fue estudiado el giro frontal medio. Una nueva y original técnica de coloración para distinguir los endosomas tempranos de la lipofuscina fue creada: se combinó el método del ácido peryódico de Schiff (PAS) para mostrar los gránulos de lipofuscina, e inmunohistoquímica del antígeno endosómico temprano (EEA1) para mostrar los endosomas tempranos.

A continuación, se estudiaron estereológicamente las láminas histológicas por el método de conteo de puntos y se calculó la fracción de volumen ocupada por el compartimento de los endosomas tempranos; se encontró esta fracción significativamente elevada en los casos de enfermedad de Alzheimer. Se estudiaron, asimismo, las láminas histológicas por el método de disector óptico y se calculó la densidad numérica de los endosomas por unidad de volumen cerebral: se observó que no hubo alteración en los casos de enfermedad de Alzheimer. La densidad numérica de los endosomas normales fue, por contraste, muy disminuída. Se concluye que el incremento en el volumen ocupado por el compartimento endosomal está relacionado con una dilatación heterogénea y no como consecuencia de la fusión endosomal. La causa del alargamiento endosomal sigue siendo desconocida, pero reciente evidencia genética señala a proteínas específicas.

Palabras clave: Alzheimer, endosomas, lipofuscina.

\section{ABSTRACT}

It is mentioned in the literature that the early endosomes are enlarged in neuronal cell body in trisomy 21 and sporadic Alzheimer disease. This alteration has never been quantified and the mechanism of this enlargement (fusion or dilation of normal endosomes) was not determined. 
We studied brains of five human corpses that suffered Alzheimer disease (AD) and five without the disease. Blocks from the middle frontal whirl were examined. A new and original technique of coloration to distinguish endosomes from lipofuscin was created: we combined the Periodic acid-schiff (PAS) method to show lipofuscin granules and immunohistochemistry of early endosomal antigen (EEA1) to reveal early endosomes.

We studied steriologically the histological laminae using the point counting method, the volume fraction occupied by the compartment of the early endosomes was calculated and we found to be significantly elevated in Alzheimer's disease; moreover, the histological laminae were studied by optical dissector method. Numerical density of endosomes per unit volume of brain was calculated and we found that it was unaltered in the case of Alzheimer's disease; however, the numerical density of normal endosomes was much diminished. We concluded that the increase in the volume occupied by the endosomal compartment was related to a heterogeneous dilation of the endosomes and was not the consequence of endosomes fusion. The cause of the endosomal enlargement remains elusive but recent genetic evidence points to specific proteins.

Key words: Alzheimer, endosomes, lipofuscin.

\section{INTRODUCCIÓN}

La enfermedad de Alzheimer (EA) se caracteriza por la presencia de placas amiloides y ovillos neurofibrilares relacionados con la agregación y formación de fibras insolubles de proteína $\beta$-amiloide y proteína Tau respectivamente. Las placas amiloides representan conjuntos insolubles de productos proteolíticos de la proteína precursora de amiloide (APP, del inglés Amyloid Precursor Protein), conocidas como péptidos $B$-amiloides, y formadas por entre 39 y 42 aminoácidos (Glenner et al. 1984) ${ }^{13}$. El mecanismo de las lesiones de la enfermedad de Alzheimer es aún desconocido, pero fuertes evidencias indican que los agregados de péptidos $\beta$-amiloides representan un evento temprano en la patogénesis de esta enfermedad, un mecanismo conocido bajo el nombre de "hipótesis de la cascada" ${ }^{10}$.

En la forma esporádica de la EA, la formación de los endosomas alargados es entendida como la primera alteración morfo- lógica detectable; aparece mucho antes de la formación de las placas seniles ${ }^{6}$. El gen de la APP está situado en el cromosoma 21, por tanto, la presencia de tres copias de APP en individuos induce la $\mathrm{EA}$, en una etapa temprana, alrededor de los 40 ańos. La presencia de tres genes de APP es suficiente para el desarrollo de la EA. De hecho, individuos con una microduplicación del gen de la APP presentan la EA alrededor de los 52 años de edad (Rovelet 2006). No está establecido todavía que es suficiente una microduplicación del gen de la APP para inducir la aparición de endosomas alargados. En modelos murinos, el gen de la APP es necesario, pero no suficiente para inducir el fenotipo "endosomas alargados" (tesis de Jack Cossec y Marie-Claude Potier).

Muchos trastornos implican defectos en la síntesis, clasificación y transporte de enzimas lisosómicas. Vías reguladoras celulares recientemente identificadas parecen controlar la orientación de proteínas hacia los lisosomas; la proteólisis por hidrolasas lisosomales, en algunas enferme- 
dades, parece ser deficiente. Estos datos sugieren que el sistema endosomal-lisosomal puede modificar las funciones de proteínas específicas. El sistema endosomal-lisosomal puede desempeñar un papel importante en la $\mathrm{EA}^{14}$.

Por endocitosis, las células son capaces de asimilar y procesar nutrientes extracelulares y factores tróficos, reciclar o degradar receptores y proteínas. La ruta principal de la endocitosis es mediada por clatrinas, pero esto también puede ocurrir a través de caveolas, macropinocitosis o fagocitosis. Las vesículas endosomales son transportadas a los endosomas tempranos, el primer paso de la ruta endocítica. Los endosomas tempranos están situados en la periferia de la célula. Son medianamente ácidos y permiten el reciclaje de muchos de los receptores a la membrana plasmática.
Los endosomas tempranos llegan a convertirse en endosomas tardíos por gemación de vesículas de transporte o directamente por maduración hacia endosomas tardíos. Los endosomas tardíos contienen material internalizado de los endosomas tempranos, pero también de la red trans-Golgi a través la vía biosintética o de los fagosomas a través de la vía fagocítica.

Los endosomas tardíos tienen un carácter ácido, mediando un conjunto final de procesos previos a la entrega del material a los lisosomas. Los lisosomas son el último compartimento de la vía endocítica y constituyen el principal compartimento hidrolítico de las células. Al llegar a un $\mathrm{pH}$ de 4,8, rico en ácido hidrolasa, están digiriendo las macromoléculas procedentes de la fagocitosis, endocitosis y autofagia; también se encargan del movimiento de proteínas citosólicas y organelas (Figura 1).

\section{FIGURA 1}

El sistema endosomal/lisosomal media la internalización, reciclaje, transporte y ruptura de componentes celulares y extracelulares y facilita la disociación de receptores de sus ligandos.

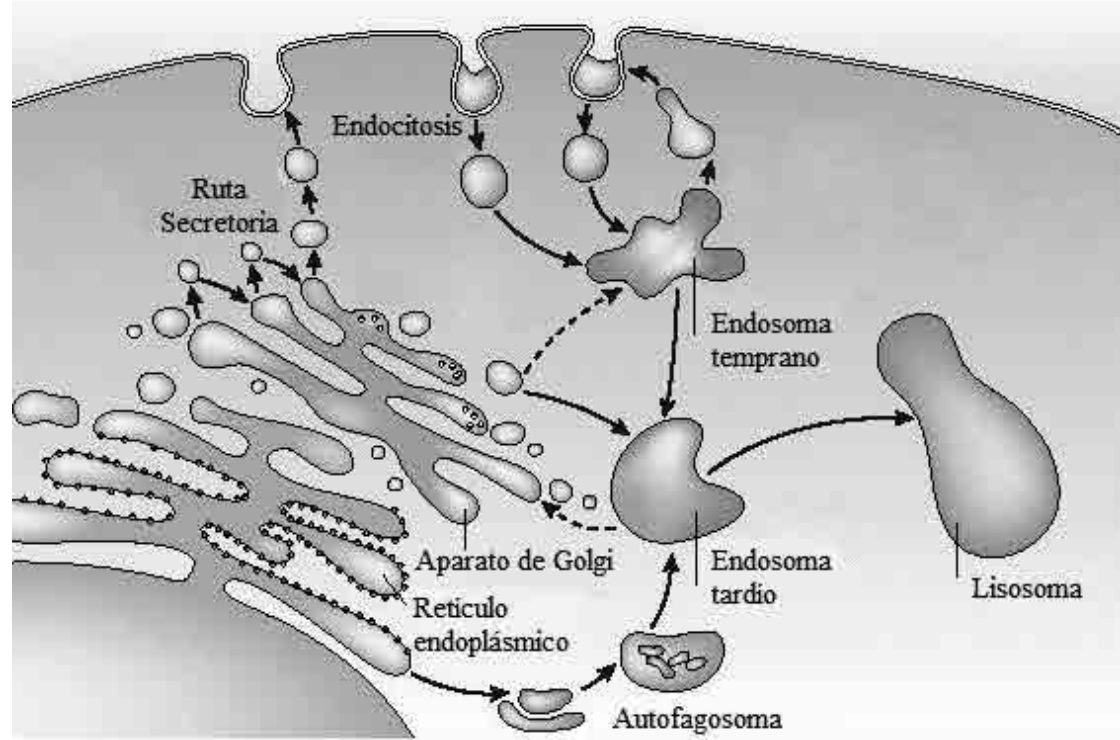

Fuente: Mylvaganam Jeyakumar, Raymond A. Dwek, Terry D. Butters \& Frances M. Platt

Nature Reviews Neuroscience 6, 713-725 (September 2005) 
Los endosomas tardíos pueden distinguirse bioquímica y biofísicamente de los endosomas tempranos y de los lisosomas, pero el debate continúa sobre si estos representan un estable y preexistente compartimento (modelo de vesícula lanzadera) o un modelo intermedio transitorio que evoluciona desde los endosomas tempranos (modelo de la maduración) ${ }^{14}$. En el modelo clásico, un preexistente y estable endosoma recibe sustratos internalizados de vesículas endocíticas tempranas y luego yemas de vesículas que reciclan receptores de membrana hacia la superficie de la célula. Un segundo grupo de vesículas transportan sustratos a lisosomas preexistentes. En el modelo de maduración alternativa los compartimentos son transitorios. Este tipo de endosomas acumulan material endocítico y se transforman gradualmente en endosomas tardíos, perdiendo la capacidad de unirse con vesículas endocíticas tempranas en el proceso.

En cortes de corteza cerebral de individuos normales, los pequeños endosomas tempranos están distribuidos cerca de la membrana celular de las neuronas. Esta localización es distinta de la de distribución predominantemente perinuclear de los endosomas tardíos, de la distribución citoplasmática uniforme de los lisosomas, y de la ubicación basal de gránulos de lipopigmento. Los endosomas tempranos normalmente tienen una forma esférica y son relativamente uniformes en tamaño (100-250 nm). Son más numerosas en el soma y las dendritas proximales. El diámetro de los endosomas tardíos y lisosomas oscila normalmente entre 100 y $400 \mathrm{~nm}$ y de 50 a $400 \mathrm{~nm}$ respectivamente. $\mathrm{Rab} 5^{3}$, GTPasa de la vía endocítica que participa en las reacciones de fusión de membrana endosomal está ausente en los endosomas tardíos y gránulos de lipofuscina, estos últimos son identificados por su gran tamaño
$(0,5$ a $1,5 \mu \mathrm{m})$ y autofluorescencia atribuida a lipopigmentos. Ellos están concentrados en la región basal del soma neuronal.

Cataldo y Nixon ${ }^{14}$ han estudiado los mecanismos celulares subyacentes a la $\beta$-amiloidogénesis en la EA esporádica y familiar, síndrome de Down (SD) y los roles de la vía endocítica y sistema lisosomal en el procesamiento de APP, que conducen a la generación de $A \beta$ (Cataldo et al, 2004). Afirman que las anormalidades de los endosomas tempranos en las neuronas piramidales de la corteza cerebral son los primeros signos patológicos específicos de la EA esporádica; aparecen mucho antes del desarrollo de los depósitos amiloides y de los ovillos neurofibrilares, aunque esta afirmación es difícil de probar en el contexto de la EA esporádica. La mayor evidencia es la coincidencia entre la aparición de endosomas alargados y el aumento inicial de la forma soluble de los péptidos $\mathrm{A} \beta 40 \mathrm{y}$ A $\beta 42$ que ocurre antes de la visible deposición amiloide ${ }^{5,4,12}$.

Según Cataldo y Nixon (2008), la prevalencia de endosomas alargados anormalmente es diez veces superior en cerebros con EA que en los cerebros control. Los endosomas alargados en un cerebro con EA miden en promedio $487 \mathrm{~nm}$ de diámetro (el diámetro promedio por cerebro va de rangos entre 400 a $620 \mathrm{~nm}$ ). Se han encontrado endosomas alargados principalmente en neuronas piramidales anormales de las capas III y V. En individuos con EA, los endosomas muestran hasta 32 veces mayores volúmenes que en los controles. Alargamiento endosomal es responsable de un aumento con una media de 2,5 veces mayor en el volumen endosomal total por neurona, implicando un incremento notable en la actividad endocítica que además induce perturbaciones en las neuronas $^{7}$ (Figura 2). 


\section{FIGURA 2}

Distribución y tamańo del sistema endosomal/lisosomal en una neurona piramidal, según Cataldo et al.

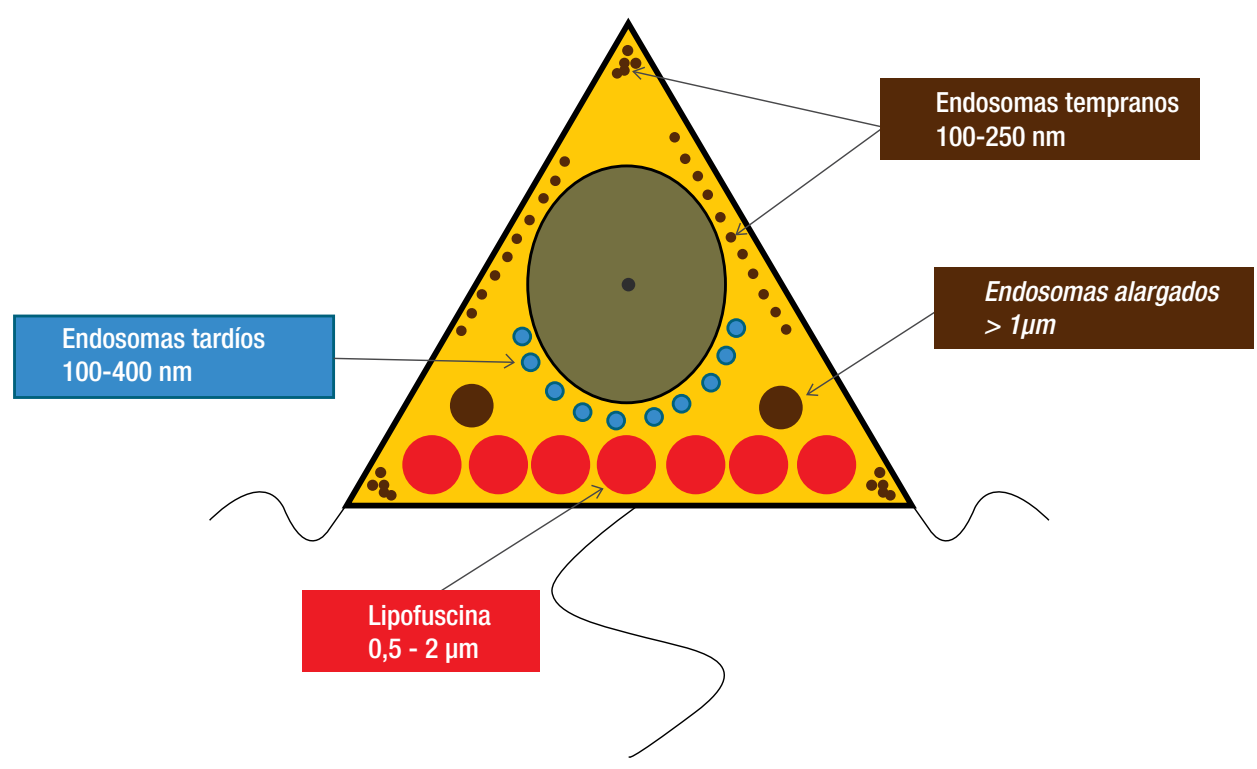

Alteraciones en la expresión y distribución de los marcadores funcionales endosomales ocurren en la EA. Los marcadores de endocitosis (Rab5), fusión (EEA1, Rabaptin5) y reciclaje (Rab4) están todos alterados, probablemente reflejando la regulación de la endocitosis. EEA1 es una proteína efectora de la fusión y acoplamiento de vesículas de membrana; asociada con Rab5, desempeña un papel crítico en la endocitosis. Como el Rabaptin-5, EEA1 forma homodímeros. EEA1 contiene dos sitios de enlace para Rab5 en su dedo de zinc N-terminal y podría desempeñar un papel en el ensamblaje de endosomas.

La actividad endocítica aumentada podría ser responsable del aumento de la interacción entre APP y BACE (del inglés beta-site APP cleaving enzyme, enzima del clivaje de la APP en el sitio $\beta$ ). BACE es una proteasa que escinde la región $\mathrm{N}$-terminal, aumentando la producción de $A \beta$. Este incremento de la actividad endocítica podría ser el mecanismo patogénico esencial en la EA esporádica y SD (Sindrome de Down). Cabe destacar que la mutación de los genes PS1 y PS2 (Presenilina 1 y 2), que juegan un rol importante en la generación de $A \beta$, no están asociados con los endosomas alargados; lo que indica que la endocitosis alterada no es consecuencia de una deposición de $A \beta^{4}$.

Los resultados de Cataldo et al. ${ }^{3,6}$, que muestran la presencia de endosomas alargados, se basan en un método de una especificidad limitada, que no permite una sutil distinción entre los endosomas alargados y los gránulos de lipofuscina. Además, el mecanismo y efecto del alargamiento de los endosomas no han sido evaluados 
cuantitativamente: ¿Es el resultado de la fusión de los endosomas? En este caso, el número de endosomas disminuirá. ¿Es la consecuencia de solo el alargamiento de una población de endosomas? En este caso, el número de endosomas seguirá siendo similar. ¿Esto induce un aumento en la fracción de volumen ocupada por el sistema endosomal? El objetivo de este estudio fue desarrollar una sensible técnica de inmunohistoquímica para la identificación de endosomas alargados con una alta especificidad en cortes de cerebro y determinar los parámetros cuantitativos del alargamiento endosomal: número de endosomas normales y alargados, fracción de volumen ocupado por los endosomas (Figura 3).

\section{MATERIAL Y MÉTODOS}

\section{Tejido}

Tejidos cerebrales post mortem fueron examinados en el laboratorio de Neuropatología Raymond Escourolle, Hôpital de La Salpêtrière, París-Francia. Después de la fijación de los cerebros en una solución tamponada de formaldehído al $4 \%$ y análisis macroscópico, muestras de hipocampo y neocórtex fueron incluidos en parafina, cortados con un espesor de $5 \mu \mathrm{m}$ y examinados luego de la coloración con $\mathrm{H} \& \mathrm{E}$ (Hematoxilina \& Eosina) y marcaje con anticuerpos Tau (clon AT8, Thermo Fisher Scientific) y A $\beta$ (clon 6F/3D, DakoCyto-

\section{FIGURA 3}

Hipótesis de los mecanismos de alargamiento endosomal
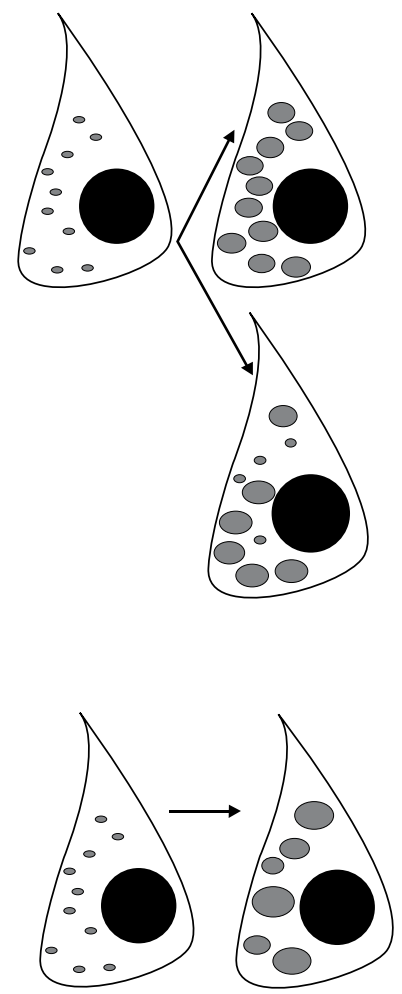

Hipótesis 1A: Alargamiento de endosomas, el número de endosomas permanece similar.

Hipótesis homogénea: todos los endosomas normales se alargan.

Hipótesis 1B: Alargamiento de endosomas, el número de endosomas permanece similar.

Hipótesis heterogénea: algunos de los endosomas normales se alargan.
Hipótesis 2: fusión de endosomas, el número de endosomas disminuye. 
mation). Los casos fueron clasificados según los estadios de Braak y Braak ${ }^{1}$.

La muestra consistió de un grupo experimental de cinco casos que reunían los criterios para el estadio severo de EA (numerosas placas amiloides y degeneración neurofibrilar en la corteza transentorrinal, entorrinal/hipocampal y en el neocórtex; estadio de Braak V-VI). El grupo control consistió de cinco casos con edades comprendidas entre 62 y 80 ańos, que resultaron ser neuropatológicamente normales (neocórtex, corteza entorrinal/hipocampal carente de placas y ovillos neurofibrilares). Fue elegido el giro frontal medial (área 10 de Brodmann), ya que permite un mejor contraste entre los casos con y sin lesiones. El hipocampo, que está involucrado en una etapa muy temprana de la enfermedad, es casi invariablemente alterado en pacientes ancianos. Los primeros experimentos fueron realizados en secciones incluidas en parafina, pero los resultados no fueron satisfactorios: los endosomas, inmunomarcados por el anticuerpo EEA1 apenas podían ser identificados. Los endosomas tempranos fueron por tanto evaluados en cortes de vibrátomo de bloques de tejido fijados en formol. Fueron estudiados tejidos cerebrales post mortem de 10 micrómetros de grosor de la corteza frontal de cadáveres.

\section{Coloración con Inmunohistoquímica: histoquímica (IHC:HC)}

Los endosomas tempranos fueron mostrados por inmunohistoquímica utilizando un anticuerpo policlonal comercial (conejo) dirigido contra el antígeno endosómico temprano 1 o EEA1 (Affinity Bioreagents, Saint Quentin en Yvelines). Los primeros ensayos en cortes de parafina indicaron que a menudo es difícil distinguir el color marrón de los pigmentos de lipofuscina del DAB (Diaminobenzidina) oxidado. Tratamos primero infructuosamente de enmascarar los gránulos de lipofuscina por diversos tratamientos previos (Sudán negro, permanganato de potasio ${ }^{15}$. Siguiendo un protocolo anterior, se recurrió a un método alternativo que consistió en la revelación de la lipofuscina en un color diferente del color de DAB oxidado ${ }^{8}$.

El método de Ziehl con fucsina mostró los pigmentos de lipofuscina en rojo, pero la coloración no resistió la deshidratación y, además, el color fue tan intenso que enmascaró el inmunomarcaje. La coloración con sulfato de Azul de Nilo también fue demasiado brillante y la deshidratación blanqueó la sección. Finalmente, la técnica del Ácido Peryódico de Schiff (PAS) distinguió muy claramente los gránulos de lipofuscina en un color violeta brillante, fácil de distinguir del color marrón de DAB. La técnica del PAS resistió a la deshidratación y no obstaculizó la inmunohistoquímica posterior. Varios ensayos indicaron, sin embargo, que la técnica de PAS debería ser realizada tras la tinción de inmunohistoquímica.

\section{¿Cortes de parafina o de vibrátomo?}

Los cortes de parafina, lo que primero usamos, pueden ser delgados $(5 \mu \mathrm{m})$ y exhiben una calidad óptica inigualable. Sin embargo, para llegar a ello, los cortes tienen que pasar por un ciclo de deshidratación, empezando por alcohol al $70 \%, 80 \%, 90 \%$ $\mathrm{y}$, finalmente, $100 \%$, seguidos por varios ciclos de xileno. Este proceso, que retira los lípidos, hace la sección más transparente y el marcaje de proteínas más delicado. Los lípidos de membrana son solubles y la identidad de las pequeñas organelas de membrana puede perderse. 
El inmunomarcaje con EEA1 en secciones de parafina es borrosa. Consideramos que esto pudo haber sido debido al tratamiento con alcohol y xileno. Esta es la razón por la que utilizamos cortes de vibrátomo, obtenidos de someter el bloque de tejido fijado con formaldehído a una hoja de afeitar vibrante. Esta técnica produce cortes en las que las membranas están preservadas. Descubrimos que una buena inmunohistoquímica con EEA1 se obtenía con estos cortes. El protocolo final combina la inmunohistoquímica con EEA1 para identificar los endosomas y PAS para mostrar los gránulos de lipofuscina.

\section{Protocolo IHC:HC (Figura 4)}

- Muestras de corteza cerebral fijadas en formol fueron cortadas con un vibrátomo en un grosor nominal de $10 \mu \mathrm{m}$. Los cortes fueron incubados en $2 \mathrm{ml}$ de TBS salino tri-tamponado (50 mM Tris, $150 \mathrm{mM}$ de cloruro de sodio, gotas de $\mathrm{HCl}, \mathrm{pH} 7,4)$ en una placa de cultivo de tejidos. Las secciones se almacenaron en TBS durante toda la noche a $4{ }^{\circ} \mathrm{C}$.

- Una dilución 1:100 de solución al $30 \%$ de peróxido de hidrógeno en metanol fue preparada inmediatamente antes de su uso para inactivar la actividad de la peroxidasa endógena en el tejido. Las secciones quedaron en la solución y la placa fue suavemente sacudida sobre una plataforma basculante durante 30 minutos. Los cortes se redujeron y arrugaron por acción del metanol.

- Tras descartar la solución de peróxido de hidrógeno en metanol, los cortes fueron enjuagados brevemente en TBS y lavados en $2 \mathrm{ml}$ de TBS durante 10 minutos, bajo un suave sacudido, a fin de eliminar todos los restos de metanol. Esta rehidratación causó la reexpansión de los cortes (las arrugas desaparecieron gradualmente).

- Los cortes de vibrátomo fueron transferidos a un frasco de vidrio Pyrex de 250 $\mathrm{ml}$, conteniendo $200 \mathrm{ml}$ de solución tampón de citrato $(50 \mathrm{mM}$ citrato trisódico dihidratado, $\mathrm{pH}$ 6,0). La concentración isotónica $150 \mathrm{mM}$ de ion sodio de este tampón impide la contracción o expansión de los cortes durante el calentamiento. El tiempo total de irradiación (para $250 \mathrm{ml}$ ) en el microondas fue de 7 minutos. La irradiación se realizó a plena potencia hasta que el tampón apenas comenzó a hervir (2 minutos). La configuración se cambia a modo autodescongelamiento (microondas intermitente entre 200 y $300 \mathrm{~W}$, con ciclos de 5-10 segundos cada 30 segundos) y los cortes fueron irradiados durante 5 minutos más. Durante este periodo, la solución se mantuvo a una temperatura de aproximadamente $95^{\circ} \mathrm{C}$; no debía hervir. El vidrio Pyrex fue retirado del horno. La solución fue dejada enfriar unos 30 minutos hasta que la temperatura descendió por debajo de $40{ }^{\circ} \mathrm{C}$. Con un suave y pequeño pincel, los cortes fueron transferidos a una placa que contenía TBS y luego cuidadosamente desplegados para eliminar arrugas y pliegues. Las secciones fueron lavadas dos veces durante 5 minutos en $2 \mathrm{ml}$ de TBS sobre una plataforma basculante.

- Los cortes fueron lavados tres veces en $2 \mathrm{ml}$ de tampón de dilución DB (TBS, $\mathrm{pH} 7.4$, suero de cabra normal $1 \%, 0,4 \%$ Triton X-100) durante 10 minutos en una plataforma basculante. Como las secciones absorben proteínas en la presencia de detergente no iónico, las arrugas observadas con soluciones que contenían Triton $\mathrm{X}-100$ desaparecieron. 


\section{FIGURA 4}

\section{Protocolo IHC:HC}

REALIZAR CORTES DE 10 $\mu \mathrm{m}$ EN VIBRÁTOMO

(Mantener los cortes de vibrátomo en TBS durante una noche a $4{ }^{\circ} \mathrm{C}$ )

BLOQUEO DE LA PEROXIDASA ENDÓGENA

( $0,3 \%$ de peróxido de hidrógeno en metanol por $30 \mathrm{~min}$ )

Lavado de los cortes en TBS por 10 min, tres veces

CALENTAMIENTO DE LOS CORTES FLOTANTES EN MICROONDAS

(Buffer citrato por 7 min a $95^{\circ} \mathrm{C}$ )

Día 1

BLOQUEO DE LOS SITIOS DE UNIÓN PROTEICA NO ESPECÍFICA

( $20 \%$ suero de cabra normal en TBS por $1 \mathrm{~h}$ )

ANTICUERPO PRIMARIO

(Dilución $1 / 250$ en DB, una noche a $4{ }^{\circ} \mathrm{C}$ )

Día 2

STREPTAVIDINA PEROXIDASA HRP

(Pomo B del KIT Dako REAL por $1 \mathrm{~h}$

Lavado de los cortes en TBS por 10 min, tres veces

DAB + CROMÓGENO

(Pomo C del KIT Dako REAL. Dilución 1/200 en Buffer Substrato HRP por 3 min)

Transferir los cortes a agua destilada para detener la reacción DAB. Lavar los cortes en agua destilada por 5 min

Lavado de los cortes en TBS por $10 \mathrm{~min}$, dos veces

Dejar secar una noche a temperatura ambiente

1 \% ÁCIDO PERYÓDICO POR 5 min

$\perp \quad$ Lavado de los cortes en agua destilada por $5 \mathrm{~min}$

REACTIVO DE SCHIFF POR $15 \mathrm{~min}$

Día 3

CONTRACOLORACIÓN EN HEMALUM DE MAYER POR $5 \mathrm{seg}$

Lavado de los cortes en agua potable por $5 \mathrm{~min}$

DESHIDRATACIÓN EN SOLUCIONES DE ALCOHOL ASCENDENTE

ACLARAMIENTO CON XILENO

MONTAJE DE LÁMINA CON DPX MOUNTING MEDIA 


\section{FIGURA 5}

Coloración combinada de IHC:HC en una neurona piramidal de un cerebro con EA. Lipofuscina en rojo en el lado izquierdo y endosomas alargados en marrón en el lado derecho de la neurona

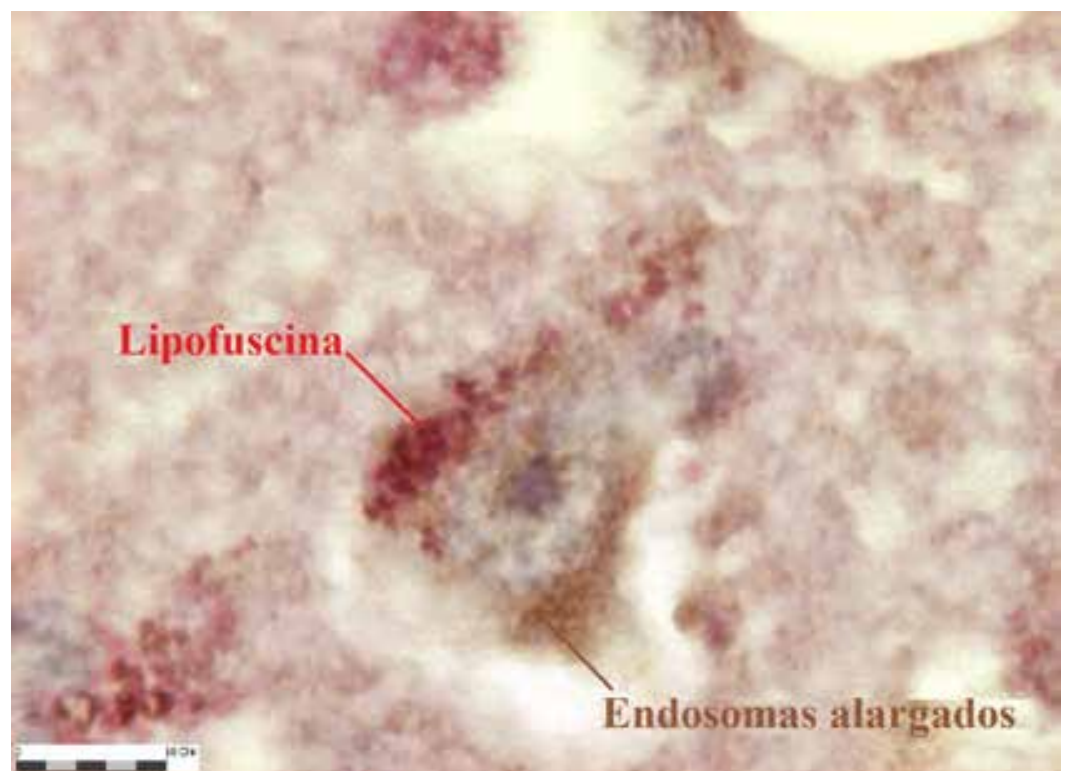

\section{FIGURA 6}

Coloración combinada de IHC:HC. En el lado izquierdo neuronas piramidales con EA con predominancia de endosomas alargados. En el lado derecho una neurona piramidal de un paciente normal con predominancia de endosomas normales

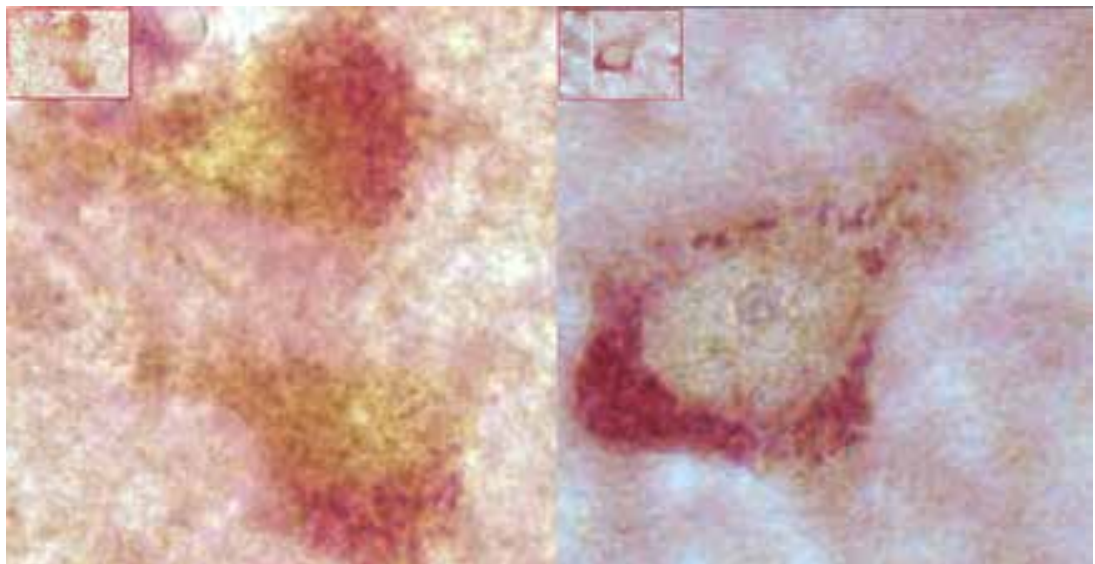




\section{FIGURA 7}

Distribución y tamańo de la lipofuscina y endosomas alargados en una neurona piramidal de un cerebro con EA
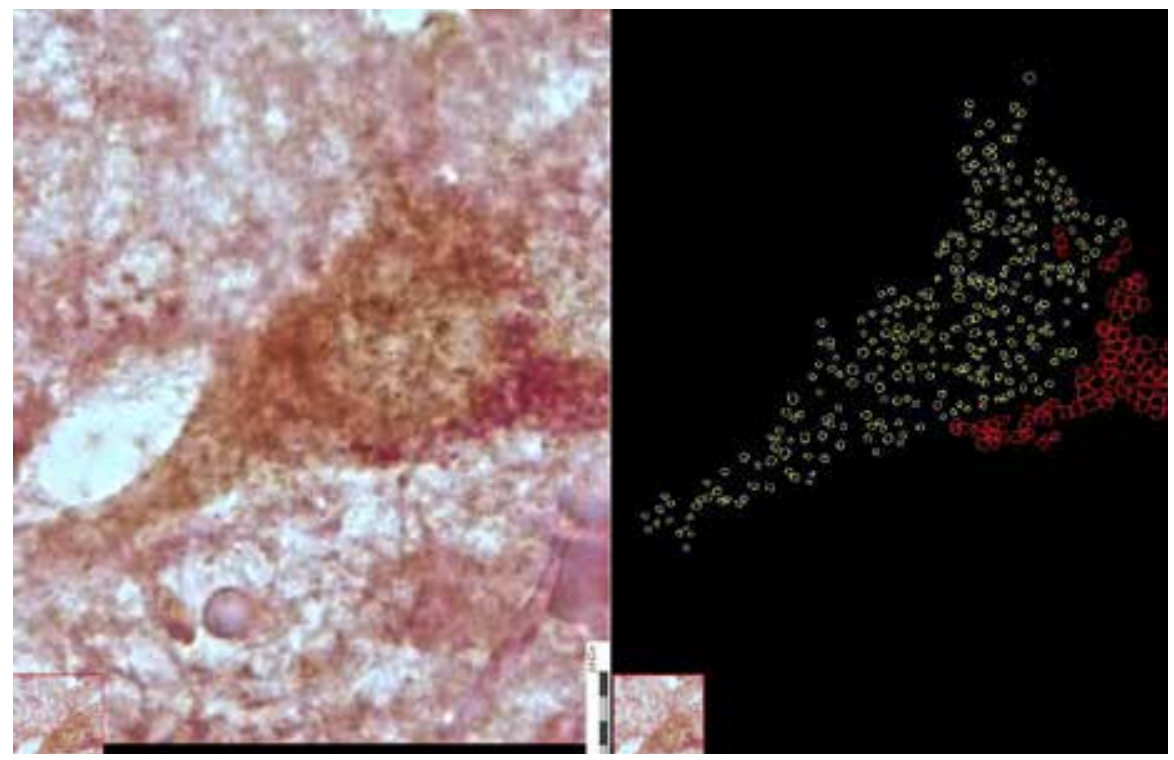

- DB fue removido y $2 \mathrm{ml}$ de filtrado estéril de $20 \%$ de suero (suero normal de cabra en TBS) fue añadido por 1 hora para bloquear los sitios de enlace proteicos no específicos en los cortes de tejido.

- Todas las soluciones de anticuerpos fueron centrifugados a $15000 \mathrm{rpm}$ en tubos microfugas durante 5 minutos, justo antes de preparar diluciones de trabajo. Esto eliminó parcialmente el anticuerpo desnaturalizado que se une de manera no específica a los cortes de tejido, aumentando la tinción de fondo. Posteriormente, las secciones fueron incubadas con anticuerpos policlonales EEA-1, dilución 1/250 en $\mathrm{DB}$, durante toda la noche a $4{ }^{\circ} \mathrm{C}$. Con diluciones $1 / 125$, la tinción de fondo era más fuerte. Diluciones $1 / 500$ y 1/000 del anticuerpo dieron resultados negativos.

- Los cortes fueron lavados tres veces durante 10 minutos en $1 \mathrm{ml}$ de DB y se in- cubaron en Biotinylated secondary antibodies (pomo A del KIT Dako Real) durante 1 hora.

- Los cortes fueron lavados tres veces durante 10 minutos en $1 \mathrm{ml}$ de DB y se incubaron en Streptavidin Peroxidase HRP (pomo B del KIT Dako Real) durante 1 hora.

- Los cortes fueron lavados tres veces durante $10 \mathrm{~min}$ en $1 \mathrm{ml}$ de TBS e incubados en $\mathrm{DAB}+$ Cromógeno (pomo $\mathrm{C}$ del KIT Dako Real), dilución 1/200 en tampón sustrato HRP durante 3 minutos.

Los cortes variaron de marrón claro a oscuro, según la cantidad de la inmunorreactividad de fondo no específica. La tinción fue controlada directamente por observación al microscopio. De 2 a 3 minutos de tinción generalmente fue lo óptimo. La reacción fue finalizada después de dos transferencias a cada corte, utilizando un peque- 
ño pincel, en una segunda placa de cultivo que contenía $2 \mathrm{ml}$ de agua desionizada.

- El agua fue retirada con una micropipeta y los cortes fueron lavados dos veces durante 10 minutos en $2 \mathrm{ml}$ de TBS.

- Alguna experiencia es necesaria para este paso, especialmente si la intención es montar varios cortes por lámina. Usando un pequeño pincel de cerdas suaves y una caja de Petri llena de TBS, los cortes fueron recogidos en láminas Super Frost ${ }^{\oplus}$ (silanizado) de vidrio. Se retiró el exceso de líquido. Las láminas se dejaron secar cara arriba sobre una superficie plana durante toda la noche, a temperatura ambiente; ello, a fin de fijar firmemente los cortes a las láminas.

- Al día siguiente, las láminas fueron incubadas en solución de ácido peryódico durante 5 minutos; luego se lavaron en agua destilada durante 5 minutos.

- Las láminas fueron incubadas además en el reactivo de Schiff (Merck) durante 15 minutos y lavadas con agua del grifo durante 10 minutos.

- Se realizó una sobretinción con Mayer' s hemalun durante 5 segundos, seguido por el lavado con agua del grifo durante 5 minutos.

- Las láminas fueron deshidratadas en tres soluciones con concentraciones ascendentes de alcohol, 15 minutos en cada uno de los alcoholes, y aclaradas con xileno durante 30 minutos.

- DPX mounting media fue utilizado para pegar el cubreobjeto.

\section{ESTEREOLOGÍA}

La evaluación cuantitativa de la densidad de los endosomas tempranos plantea va- rios problemas: 1) los endosomas son objetos pequeños en el límite del poder de resolución del microscopio de luz; 2) ellos son tan abundantes en el citoplasma que es imposible contarlos todos; 3) su tamaño cambia: la posibilidad de incluir a los endosomas alargados en el corte es mayor que la probabilidad de hacerlo con los pequeños endosomas. Un recuento ingenuo podría sesgar los resultados hacia una sobreestimación de los endosomas alargados.

Para tratar estos problemas hemos decidido utilizar dos métodos de evaluación:

1) La medición del área ocupada por el endosoma en relación con la superficie total del citoplasma.

Esta densidad de área es directamente proporcional a la densidad de volumen según el principio de Delesse $\left(\mathrm{V}_{\mathrm{v}}=\mathrm{AA}\right)$. Fue utilizado el método del conteo de puntos. Para ello, utilizamos una filmina transparente con una rejilla rectangular dibujada con 368 puntos de prueba o test points (PT), una distancia (d) entre los puntos de prueba de $2,85 \mu \mathrm{m}$; la rejilla fue fijada a la pantalla del ordenador. La imagen de un campo microscópico fue examinada en la pantalla a través de una cámara adaptada al fototubo del microscopio. Fueron evaluados el número de puntos de prueba situado sobre las estructuras inmunorreactivas EEA1 $\left(\mathrm{N}_{+}\right)$y los puntos de prueba situados fuera de ellas (N-). La fracción de área AA fue estimada mediante la razón $\mathrm{N}_{+} /(\mathrm{N}-+\mathrm{N}+)$. Diez campos fueron evaluados en cada caso. Un estudio piloto mostró que con este esquema de muestreo el coeficiente de error fue lo suficiente bajo, entre 3 y $5,3 \%$.

2) La evaluación del número de endosomas.

Se utilizaron muestras muy pequeñas de $8,12 \mu \mathrm{m} 2$ (para disminuir el número de objetos) y el método disector, a fin de evi- 
tar la sobreestimación de los endosomas alargados. El espesor de los cortes microscópicos se determinó con un microcator y resultó ser de $5,8 \mu \mathrm{m}$ en promedio. El volumen de la muestra fue de $8.12 \times 5,8$ $=47,1 \mu \mathrm{m}^{3}$. Este volumen se examinó sistemáticamente desde la superficie superior de la lámina hasta la superficie inferior utilizando un lente objetivo con una gran apertura numérica (NA 1,25; objetivo $\mathrm{x} 100$ ). El tornillo micrométrico fue utilizado para examinar sucesivamente los distintos planos ópticos. Fueron contados solo los objetos que se ven y desaparecen con el cambio de enfoque. Este método, denominado microdisección óptica, resulta en contar solamente el polo inferior de los objetos (aquí, los endosomas). El polo es un punto virtual de dimensión 0 que es, por tanto, no sesgada. Se contaron cinco campos por caso.

\section{RESULTADOS}

\section{Observación cualitativa con el protoco- lo de coloración combinado IHC: HC}

En material post mortem, es difícil distinguir los gránulos de lipofuscina de una señal inmunohistoquímica o inmunofluorescente. La lipofuscina, de hecho, aparece de color marrón cuando el DAB ha sido utilizado como cromógeno; es autofluorescente $y$, por tanto, puede ser confundido con la fluorescencia roja o verde del anticuerpo secundario. La extinción de la fluorescencia al utilizar Sudán negro parece ser difícil de controlar y podría además extinguir la inmunofluorescencia. Por tanto, fue necesario un método que permitiera la distinción de los aspectos positivos y las señales espurias por medio de distintos colores.

La combinación de IHC:HC (Figura 5) permitió una buena diferenciación de la lipofuscina y de los endosomas alargados, además de una colocalización de estos dos elementos en el mismo corte de tejido. Con el vibrátomo obtuvimos una buena coloración de los endosomas en marrón y una fuerte tinción de lipofuscina en rojo cuando el tiempo de incubación de PAS fue de 30 minutos. Se redujo el tiempo de tinción de PAS por la mitad y se encontró que el equilibrio entre el marrón de la inmunohistoquímica y el púrpura de PAS fue satisfactoria. Este enfoque novedoso indicó que aunque hay algunas colocalizaciones detectables, la mayoría de los gránulos de lipofuscina y endosomas alargados ocupan distintos compartimentos celulares en las neuronas de los cerebros normales (control) y cerebros con EA (Figura 6). Además, los gránulos de lipofuscina fueron, en promedio, tres veces más grandes que los endosomas alargados.

Como se ha descrito previamente en la literatura, los endosomas tempranos son esféricos y relativamente uniformes en tamaño (100-250 nm) en cerebros normales controles. En cerebros con EA, encontramos que los endosomas tempranos son significativamente alargados; presentan un diámetro de entre 400 y 1,4 $\mu \mathrm{m}$ (Figura 7).

\section{DENSIDAD DE ÁREA DE ENDOSOMAS POR NEURONA}

La superficie total ocupada por los endosomas tempranos (tanto normales como alargados) fue de $49 \%+/-2.9 \%$ en los controles (media $+/$ - error estándar de la media) y $66 \%+/-2 \%$ en los casos con $\mathrm{EA}(\mathrm{t}=4,4 ; \mathrm{p}<0,003)($ Tablas 1 y 2$)$.

\section{Número de endosomas por $\mu^{3}$}

La densidad de endosomas fue de 0,52 +/$0,04 / \mu \mathrm{m}^{3}$ para los casos con EA y de 0,42 $+/-0,03 / \mu \mathrm{m}^{3}$ para los controles. La dife- 
TABLA 1

Densidad de superficie de endosomas por neurona. A, total de endosomas por neurona. $\mathrm{B}$, endosomas alargados por neurona. $\mathrm{C}$, endosomas normales por neurona

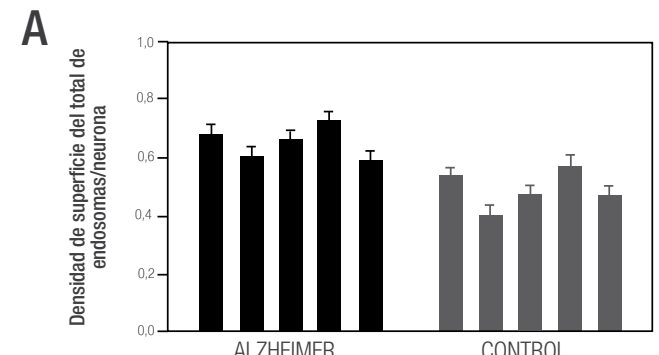

B

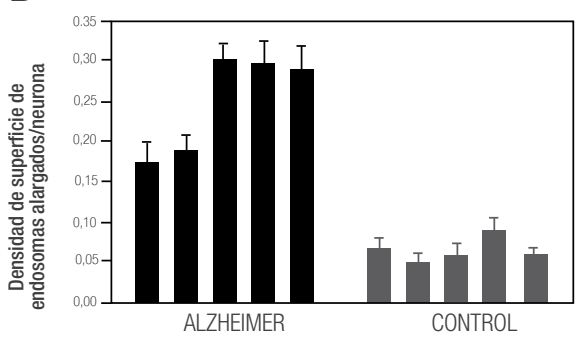

C

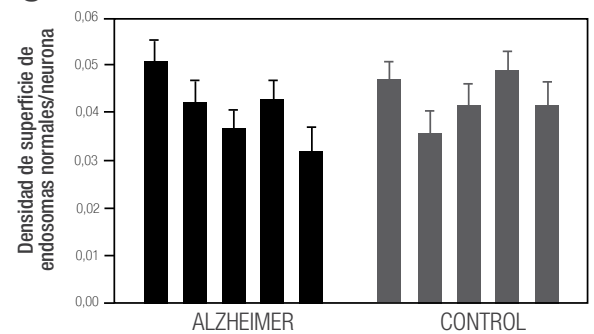

TABLA 2

Media de la densidad de superficie de endosomas por neurona. A, total de endosomas por neurona. $\mathrm{B}$, endosomas alargados por neurona. $\mathrm{C}$, endosomas normales por neurona
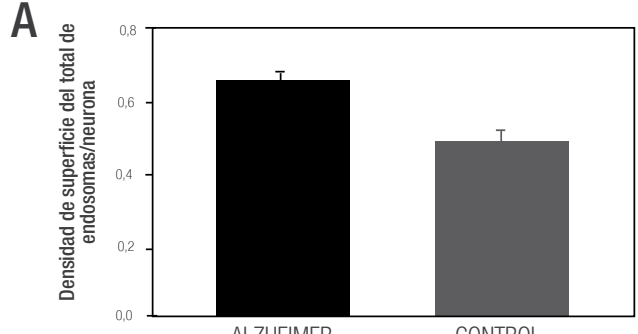

B

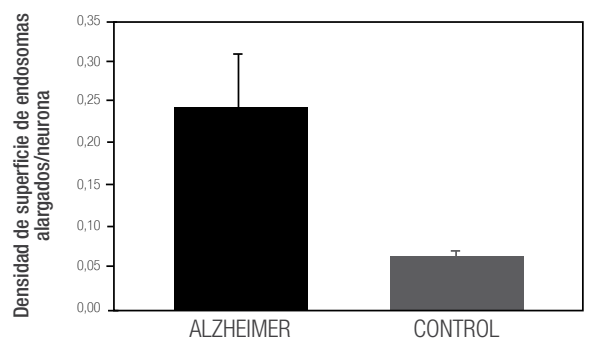

C

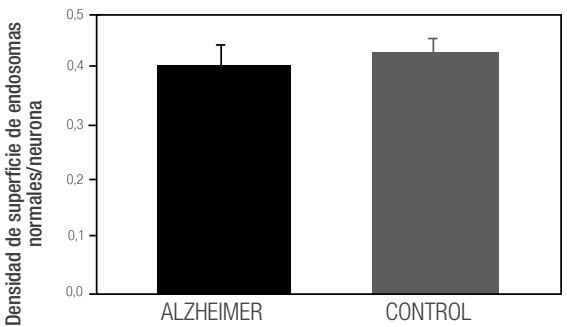


rencia no fue estadísticamente significativa $(p=0,10)$. Desde que los endosomas normales resultaron ser reconocibles por su tamaño y fueron totalmente incluidos en el volumen, también se evaluó la densidad de endosomas normales. Se encontró un valor de $0.12+/-0.008 / \mu \mathrm{m}^{3}$ para los casos de EA y $0.26+/-0.013$ para los controles. La diferencia fue altamente significativa (test: $\mathrm{p}=0.00001$ ) (Tablas 3 y 4).

\section{DISCUSIÓN}

Se evaluó la fracción de volumen ocupada por el compartimiento endosomal temprano y se descubrió que era mayor en el grupo de pacientes con EA de forma estadísticamente significativa. Utilizando el método disector (método validado), se ha demostrado que la densidad numérica de los endosomas por $\mu \mathrm{m}^{3}$ no se ha modificado, aunque la proporción de endosomas normales resultó ser baja en EA.

\section{La lipofuscina, localización subcelular}

Cataldo et al. ${ }^{3}$ han demostrado que la lipofuscina está concentrada en el polo basal del soma celular. Contrariamente a esta observación, hemos encontrado la lipofuscina a menudo agrupada como granos, distribuida en el citosol. El protocolo de coloración combinada IHC:HC para lipofuscina y endosomas alargados en cerebros con EA fue desarrollado para permitir la diferenciación entre estas dos estructuras en la neurona y para eliminar posibles falsos positivos de lipofuscina por coloración de artefactos. Además, este nuevo protocolo combinado de IHC:HC puede ser usado para investigar la distribución espacial de otras proteínas relativas a la lipofuscina.

La coloración diferencial es importante, pero hay otras características que distinguen la lipofuscina y endosomas alargados: el mayor tamaño de las vesículas de lipofuscina frente a los endosomas alargados o no alargados, y sus diferentes formas: cuadradas y rectangulares (gránulos de lipofuscina) en contraposición a la forma circular (endosomas).

\section{Modificación del compartimento endo- somal en la EA}

Se midió la densidad de área de los endosomas y el número total de endosomas en la EA y en los controles; se encontró una diferencia significativa con la medición de la densidad de área. Por primera vez, se evaluó cuantitativamente la fracción de volumen incrementada del compartimento endosomal temprano. Este aumento es bastante significativo y sugiere que hay un aumento de la endocitosis en la EA (aunque otros escenarios son posibles). Dos posibilidades principales tienen que ser consideradas: los endosomas alargados podrían ser la consecuencia de la fusión de endosomas normales. En este caso, sería de esperar una disminución en el número total de endosomas. En la otra hipótesis, se podría imaginar que todos o algunos de los endosomas normales tornan alargados. En esta hipótesis, el número total de endosomas quedaría inalterado. Esto es, de hecho, lo que hemos encontrado. El número total de endosomas por $\mu \mathrm{m}^{3}$ no fue significativamente diferente entre los casos con EA y los del grupo control. El alargamiento con número inalterado podría tener lugar en dos formas diferentes: todos los endosomas normales podrían alargarse ligeramente (hipótesis homogénea) o algunos de ellos se alargan de manera significativa (hipótesis heterogénea). La persistencia de una población normal de endosomas en el grupo de casos EA está a favor de esta última hipótesis. 


\section{TABLA 3}

Número de endosomas por $\mu^{3}$. A, total de endosomas por $\mu^{3}$. B, endosomas alargados por $\mu^{3}$. C, endosomas normales por $\mu^{3}$

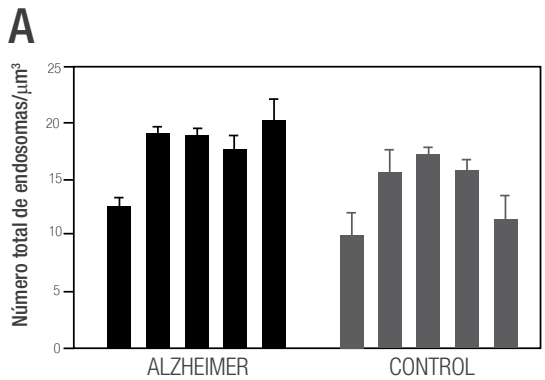

B

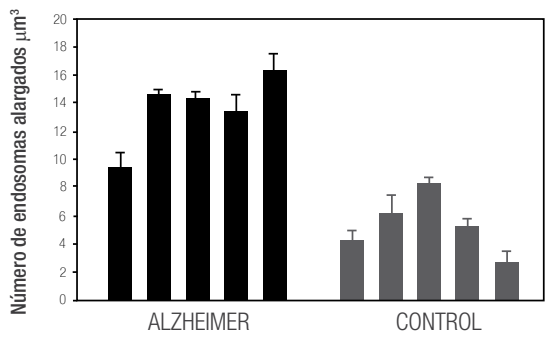

C

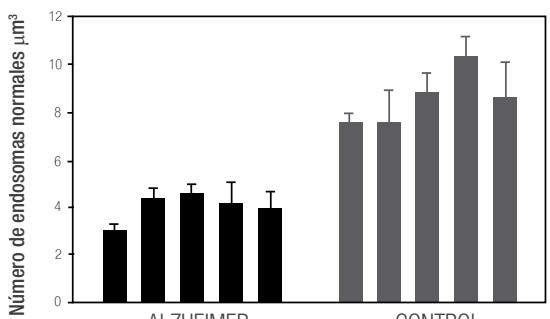

ALZHEIMER

CONTROL

TABLA 4

Media del número de endosomas por $\mu \mathrm{m}^{3}$. A, total de endosomas por $\mu^{3}$. B, endosomas alargados por $\mu \mathrm{m}^{3}$. C, endosomas normales por $\mu^{3}$

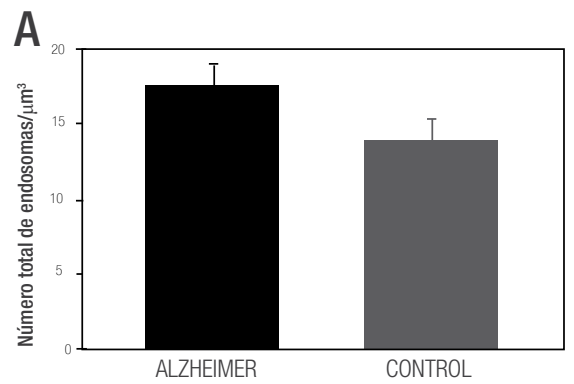

C
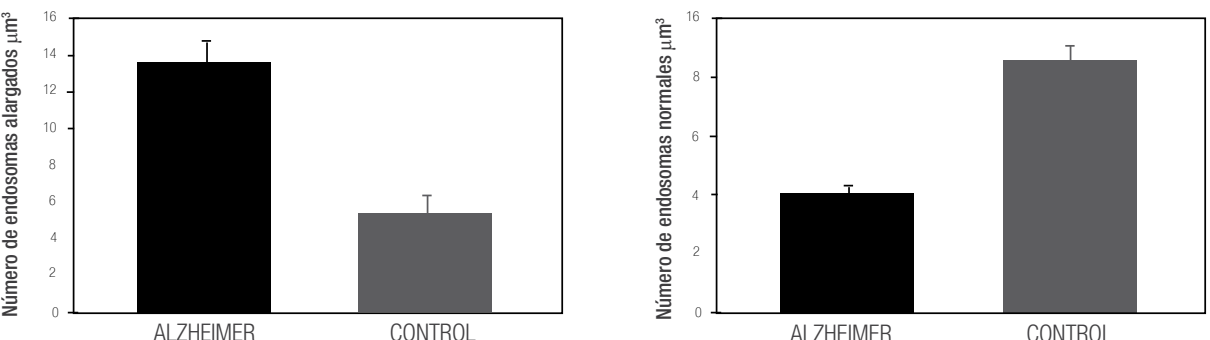

ALZHEIMER

CONTROL 
En conclusión, nuestro estudio permite describir un escenario de la alteración del compartimiento de endosomas tempranos. Una alteración inicial que sigue sin determinarse induce la ampliación de una porción significativa del compartimento endosomal sin fusión. La alteración inicial puede ser discutida: podría ser secundaria a un aumento de la endocitosis. Sin embargo, el proceso parece ser bastante específico a la EA y, por tanto, es plausible que un cambio específico modifique este compartimento.

Este cambio específico también podría ser un defecto en el despeje del endosoma temprano desde la periferia del citoplasma, un mecanismo en el que participan varias proteínas. Un estudio, en preparación en laboratorio, intenta identificar los genes específicos que son necesarios para obtener el fenotipo endosoma alargado en la trisomía 21. La duplicación parcial ha limitado el número de posibles genes. Uno de ellos parece estar específicamente involucrado.

\section{REFERENCIAS BIBLIOGRÁFICAS}

1. Braak H, Braak E. Neuropathological stageing of Alzheimer-related changes. Acta Neuropathol. 1991. 82(4):239-59.

2. Callaghan J, Simonsen A. The endosome fusion regulator early-endosomal autoantigen 1 (EEA1) is a dimer. Biochem. J. 1999. 338, 539-543.

3. Cataldo AM, Jody LB, Pieroni C, Nixon $R A$. Increased neuronal endocytosis and protease delivery to early endosomes in sporadic Alzheimer's Disease: Neuropathologic evidence for a mechanism of increased $\beta$-amyloidogenesis. 1997.

4. Cataldo AM, Peterhoff CM, Troncoso JC, Gomez-Isla T, Hyman BT, Nixon RA.
Endocytic pathway abnormalities precede amyloid $\beta$ deposition in sporadic Alzheimer's disease and Down syndrome. Am J Pathol. 2000. 157(1): 277-286.

5. Cataldo AM, Petanceska S. A $\beta$ localization in abnormal endosomes: association with earliest $A \beta$ elevations in $A D$ and Down syndrome. Neurobiology of Aging. 2004. 25: 1263-1272.

6. Cataldo AM, Petanceska S, Terio NB, Peterhoff CM, Durham R, Mercken M, Mehta PD, Buxbaum J, Haroutunian V, Nixon RA. A $\beta$ localization in abnormal endosomes: association with earliest $A \beta$ elevations in $\mathrm{AD}$ and Down syndrome. Neurobiol Aging. 2004. 25: 1263-72.

7. Cataldo AM, Mathews PM, Boiteau AB, Hassinger LC, Peterhoff CM, Jiang Y, Mullaney K, Neve RL, Gruenberg J, Nixon RA. Down syndrome fibroblast model of Alzheimer-related endosome pathology: accelerated endocytosis promotes late endocytic defects. Am J Pathol. 2008. 173(2):370-84.

8. D'Andrea MR, Nagele RG, Gumula NA, Reiser PA, Polkovitch DA, Hertzog BM, Andrade-Gordon P. Lipofuscin and Abeta42 exhibit distinct distribution patterns in normal and Alzheimer's disease brains. Neurosci Lett. 2002. 323: 45-9.

9. Dunnigan MG. The use of Nile blue sulphate in the histochemical identification of phospholipids. Stain Technol. 1968 43: 249-56.

10. Hardy JA, Mann DMA, Wester P. An integrative hypothesis concerning the pathogenesis and progression of Alzheimer's disease. 1986. Neurbiol Aging 7: 489.

11. Jeyakumar M, Dwek RA, Butters TD, Platt FM. Storage solutions: treating lysosomal disorders of the brain. Nat Rev Neurosci. 2005. 6(9):713-25. 
12. Laifenfeld D, Patzek LJ. Rab5 mediates an amyloid precursor protein signaling pathway that leads to apoptosis. J. Neurosci. 2007. 27(27):71417153.

13. Kang J, Lemaire H-G, Unterbeck A, Salbaum JM, Masters CL, Grzeschik KH, Multhaup G, Beyreuther K, Muller-HiIl B.The precursor of Alzheimer's disease amyloid A4 protein resembles a ce11-surface receptor. Nature. 1987. 325: 733-736).

14. Nixon RA, Cataldo AM. The endosomal-lysosomal system of neurons: new roles. Trends Neurosci. 1995. 18: 489-496.
15. Schnell SA, Staines WA, Wessendorf MW. Reduction of lipofuscin-like autofluorescence in fluorescently labeled tissue. J Histochem Cytochem. 1999. 47: 719-30.

16. Sterio DC. The unbiased estimation of number and sizes of arbitrary particles using the disector. J Microsc. 1984. 134: 127-136).

17. Woodman PG. Biogenesis of the Sorting Endosome: The Role of Rab5. Traffic. 2000. 1(9): 695-701.

18. Weibel ER. Stereological methods. Practical methods for biological morphometry. 1979. Vol. 1. Academic Press, London. 